\title{
REVIEW
}

\section{Why Topical Retinoids Are Mainstay of Therapy for Acne}

James Leyden $\cdot$ Linda Stein-Gold $\cdot$ Jonathan Weiss

Received: April 25, 2017 / Published online: June 5, 2017

(C) The Author(s) 2017. This article is an open access publication

\begin{abstract}
Acne-focused dermatology expert groups have consistently recommended that most patients with acne be treated with a combination of topical retinoid and antimicrobial therapy. This is based on clinical data as well as evidence that these drug classes have different and complementary mechanisms of action that target multiple aspects of acne's complex pathophysiology. Recent evidence-based guidelines for acne, including those from the American Academy of Dermatology (AAD) and the European Dermatology Forum (EDF), have agreed that retinoids have an essential role in this widespread disease. The AAD states "retinoids are the core of topical therapy for acne because they are comedolytic, resolve the precursor
\end{abstract}

Enhanced content To view enhanced content for this article go to http://www.medengine.com/Redeem/ 2698F0606E2CE7C5.

J. Leyden $(\bowtie)$

Department of Dermatology, University of

Pennsylvania School of Medicine, Philadelphia, PA, USA

e-mail: jjleyden@mindspring.com

L. Stein-Gold

Department of Dermatology, Henry Ford Hospital,

Detroit, MI, USA

J. Weiss

Gwinnett Dermatology, PC, and Gwinnett Clinical

Research Center, Inc., Snellville, GA, USA microcomedone lesion, and are anti-inflammatory;" further, they "allow for maintenance of clearance." Despite uniform recommendation for use of topical retinoids, a recent study of prescribing practices from 2012 to 2014 indicated that dermatologists prescribed retinoids just $58.8 \%$ of the time while non-dermatologists prescribed them for only $32.4 \%$ of cases. In this article, we review the reasons supporting retinoids as the mainstay of acne therapy and discuss some of the perceived barriers that may be limiting use of this important drug class. Further, we discuss how and when titrating retinoid concentrations may be utilized in clinical practice.

Funding: Galderma International.

Keywords: Acne vulgaris; Adapalene; Tazarotene; Topical retinoid; Tretinoin

\section{INTRODUCTION}

In 2016, the burden of acne vulgaris-a chronic inflammatory skin disease-was estimated to be approximately $\$ 3$ billion in healthcare costs and lost productivity in the USA [1]. This underscores the fact that acne is an important disease, worthy of attention, and not just a simple adolescent complaint. Over the past decade, a number of consensus recommendations and evidence-based guidelines have been 
created to help guide clinicians in selection of treatments for acne [2-7]. Acne-focused expert groups within the dermatology community, including the American Acne and Rosacea Society and the Global Alliance to Improve Outcomes in Acne, have consistently recommended that most patients with acne be treated with a combination of topical retinoid and antimicrobial therapy [2-4]. The recommendations are based on both clinical trial data from thousands of patients and bench data showing the drug classes have different and complementary mechanisms of action that target multiple aspects of acne's complex pathophysiology [2, 3]. Recent evidence-based guidelines for acne, including those from the American Academy of Dermatology (AAD) and the European S3 guidelines from the European Dermatology Forum (EDF), have agreed that retinoids have an important role in this widespread disease $[5,7]$. The AAD guidelines state that "retinoids are the core of topical therapy for acne because they are comedolytic, resolve the precursor microcomedone lesion, and are anti-inflammatory;" furthermore, they "allow for maintenance of clearance" [7].

Yet both our anecdotal experiences from interacting with other physicians and more recent data have confirmed past studies indicating that topical retinoids are under-used for acne $[1,8,9]$. In a data set from the American insurance company Humana that included 87,970 individuals with acne who consulted dermatologists $(n=74,371)$ or non-dermatologist physicians $(n=13,599)$, dermatologists were almost twice as likely to prescribe a retinoid when compared with non-dermatologists (58.8\% vs. $32.4 \%$ ) [1]. A high proportion of dermatologists $(41.2 \%)$ and a significant majority (67.6\%) of non-dermatologists did not prescribe retinoids [1]. Both dermatologists and other physicians were less likely to prescribe a retinoid for patients aged 19 or older compared to those aged 10-19 [1]. Due to these data, we would like to review the evidence supporting why retinoids should be considered the foundation of acne therapy (with a focus on topical retinoids) and suggest how to overcome some of the perceived barriers to use. This article is based on previously conducted studies and does not involve any new studies of human or animal subjects performed by any of the authors.

\section{Role of Retinoids in Acne Management}

It is generally agreed that multiple molecular pathways are involved in acne, with four primary pathophysiologic mechanisms $[3,10,11]$ :

- Abnormal desquamation within the sebaceous follicles that leads to obstruction of the pilosebaceous canal.

- Androgen-driven excess sebum production.

- Proliferation within the follicle by Propionibacterium acnes, which generates proinflammatory stimuli.

- Altered immune system activity and inflammation.

While there is an interplay among the pathogenic factors, abnormal desquamation and sebaceous hyperplasia are arguably the most important because together they are thought to induce the microcomedone-the precursor of all acne lesions [11-13]. The essential action of inflammation in all ongoing processes of acnefrom the initiation of the microcomedone to the secondary lesions (typically long-lasting sequelae such as scars and pigmentation that are very bothersome for the patient)—is also increasingly appreciated [12, 14-17].

Topical retinoids (adapalene $0.1 \%$ and $0.3 \%$; tazarotene $0.1 \%$; tretinoin $0.01 \%, 0.025 \%$, $0.038 \%, 0.04 \%, 0.05 \%, 0.08 \%$, and $0.1 \%$ in the USA; isotretinoin $0.05 \%$ and $0.1 \%$ in other regions of the world) have a central role in acne therapy because they have been shown both to reduce visible lesions and also inhibit the development of microcomedones and new lesions [12, 18]. Retinoids act to normalize desquamation by reducing keratinocyte proliferation and promoting differentiation [19]. Topical retinoids also block several important inflammatory pathways that are activated in acne: Toll-like receptors, leukocyte migration, and the AP-1 pathway $[19,20]$. In the case of adapalene, these molecular actions have been shown to be dose dependent (Fig. 1) [21]. However, it is clear that isotretinoin, tretinoin, 


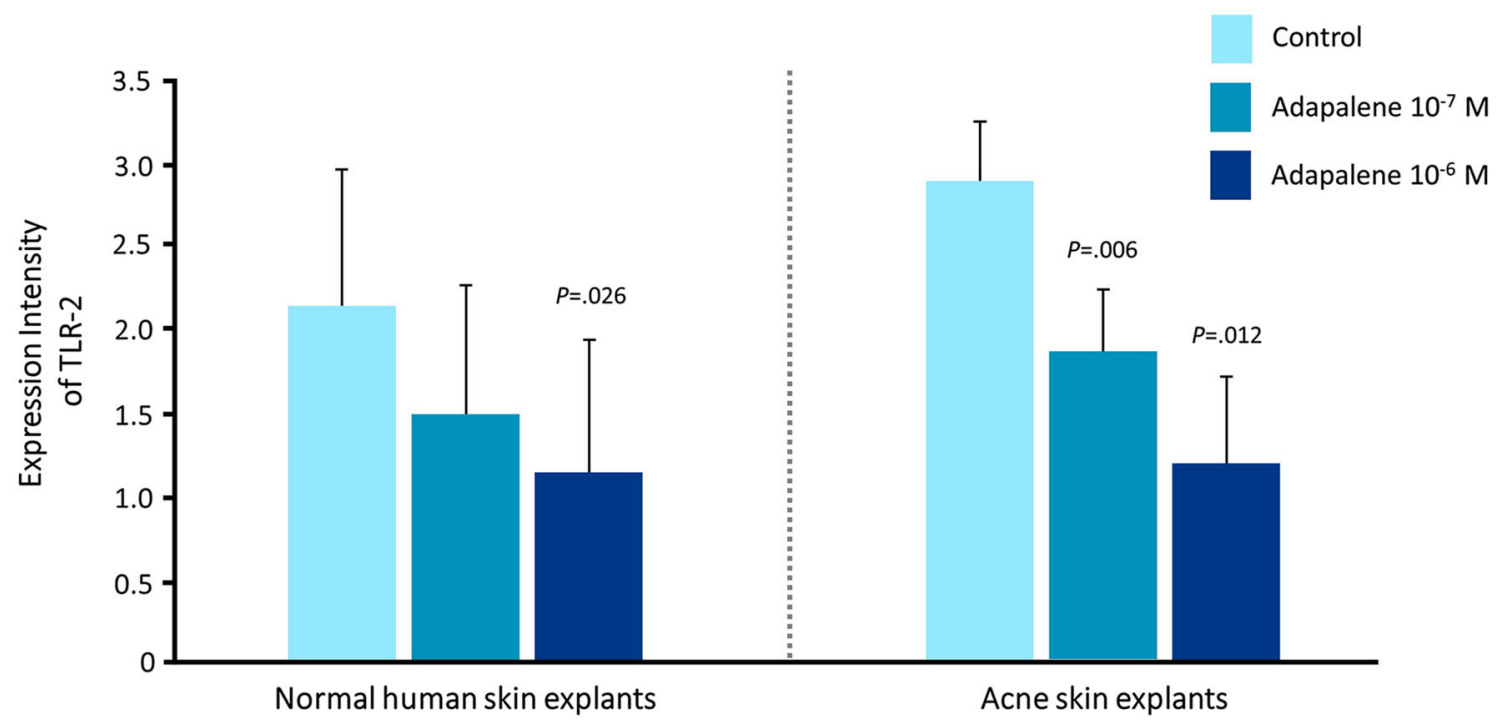

Fig. 1 Dose-dependent actions of adapalene at the molecular level. From Tenaud et al. [21]

and tazarotene also suppress Toll-like receptor expression. Blocking these pathways reduces the release of inflammatory cytokines and nitric oxide and inhibits cellular inflammation $[2,19,22,23]$.

\section{Dose-Dependent Effects on Primary Acne Lesions}

The efficacy of individual topical retinoids increases with increasing concentration. Tretinoin was first shown to have dose-dependent effects in animal models [24]. In two separate ultra-structural studies, 12 weeks of tretinoin therapy $(0.1 \%$ and $0.025 \%)$ reduced microcomedones by $80 \%$ and $35 \%$, respectively $[18,25]$. Registration studies of adapalene gel $0.3 \%$ consistently showed superior dose-related efficacy with adapalene $0.3 \%$ vs. $0.1 \%$ across all efficacy measures, with good tolerability at both dosages $[26,27]$. Analysis of the phase III study of adapalene gel $0.3 \%$ showed that the greatest efficacy was achieved in patients who had higher lesion counts at baseline [26].

Most recently, the fixed combination adapalene $0.3 \%$-benzoyl peroxide (BPO) $2.5 \%$ (0.3 A/BPO; Epiduo Forte ${ }^{\circledR}$, Galderma Laboratories) has shown efficacy in a patient population with substantially more severe acne than is typically treated by topical monotherapy [28]. The higher concentration $0.3 \mathrm{~A} / \mathrm{BPO}$ was associated with higher clinical success rates and efficacy on all types of acne lesions (Fig. 2) [28].

\section{Effects on Secondary Acne Lesions}

In addition to affecting primary acne lesions, topical retinoids have also been shown to act on secondary lesions including scarring and pigmentation because of actions in the dermis. Acne scarring occurs as a result of dermal remodeling and an imbalance between matrix degradation and matrix synthesis that is orchestrated by matrix metalloproteinases (MMPs) [29]. An open-label pilot study of adapalene $0.3 \%$ in subjects with acne scarring showed improvement of one or two grades on a scar assessment scale by week 24 , along with better overall skin texture [30]. Further, adapalene $0.3 \%$ was associated with upregulation of procollagen genes and increases in procollagen-1 staining plus collagen-3 staining [30].

In pigmentary problems, topical retinoids lighten hyperpigmented lesions by inhibiting melanosome transfer to keratinocytes and reducing epidermal pigmentation by accelerating epidermal turnover [31]. Grimes et al. reported tazarotene $0.1 \%$ cream was effective for acne-related PIH, significantly reducing pigmentation intensity and area over 18 weeks compared with vehicle $(P \leq 0.05)$ [32]. In a study comparing tazarotene $0.1 \%$ cream versus 


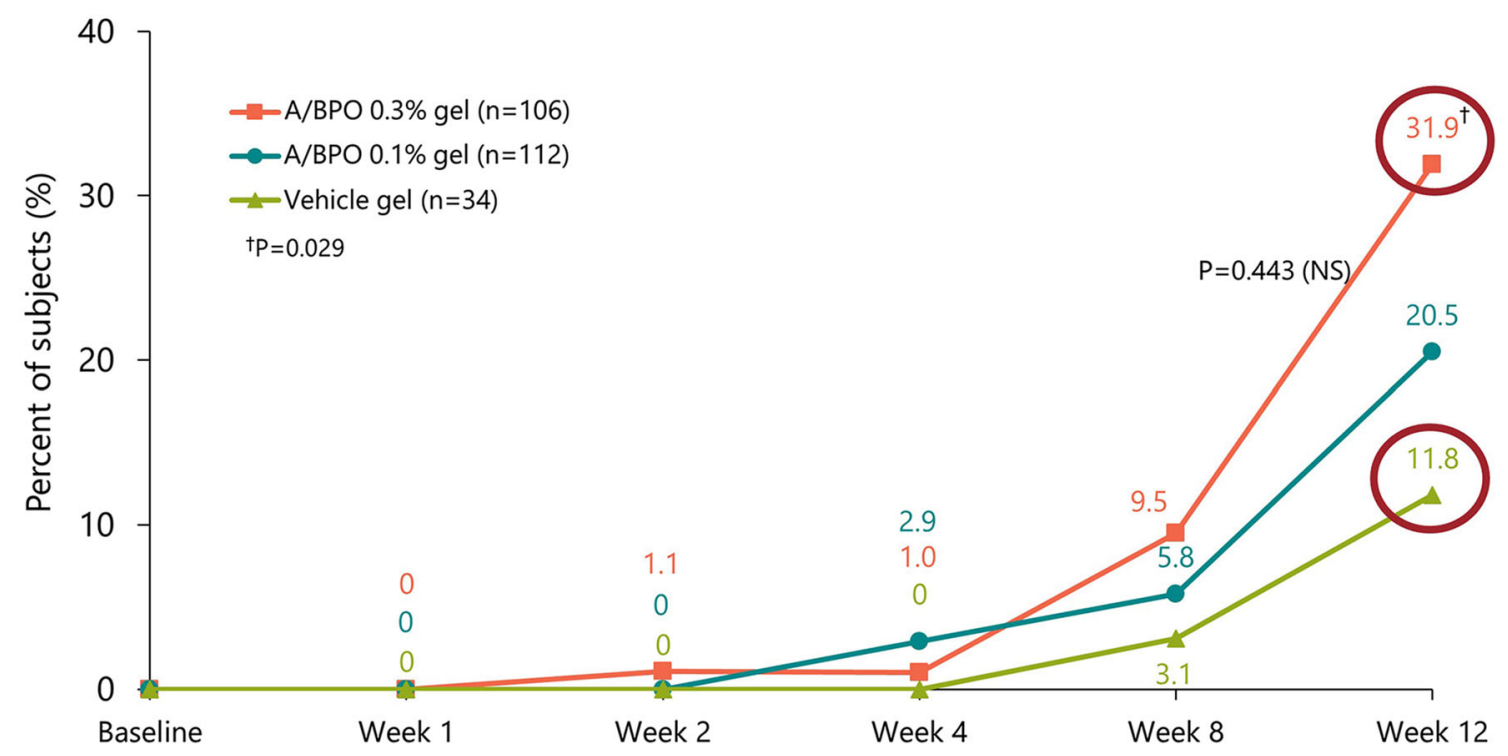

Fig. 2 Dose-dependent clinical success rate (IGA) of $0.3 \mathrm{~A} / \mathrm{BPO}, \mathrm{A} / \mathrm{BPO}$, and vehicle in patients with severe acne at baseline. From Weiss et al. [68]

adapalene $0.3 \%$ gel, Tanghetti et al. reported that 16 weeks of tazarotene significantly decreased PIH in acne patients; adapalene reduced $\mathrm{PIH}$ but did not achieve significant differences from baseline [33]. In addition, 25\% $(10 / 40)$ of the tazarotene-treated subjects had complete resolution of PIH [33]. Griffiths et al. found that tretinoin $0.1 \%$ cream improved pigmentation in melasma patients, with an effect that was significantly superior to vehicle $(P=0.0006)$ [34]. In an open-label study of South African acne patients with dark skin types, adapalene gel $0.1 \%$ reduced both the number of pigmented macules and the density of hyperpigmentation to a degree "comparable to that observed for topical tretinoin," according to the author [35]. In a 40-week study, Bulengo-Ransby et al. found that facial post-inflammatory hyperpigmented lesions of tretinoin-treated subjects were significantly lighter than those of vehicle-treated subjects $(P<0.001)$ [36].

\section{Perceived Barriers to Use of Retinoids}

\section{Efficacy in Inflammatory Acne}

There is a common perception that retinoids should be reserved primarily for comedonal acne [37]. Randomized controlled trials have provided strong evidence that topical retinoids as monotherapy significantly reduce inflammatory lesions, with an effect that is comparable to that on noninflammatory lesions (Fig. 3) [38-40]. The beneficial effect of topical retinoids on inflammatory lesions is clear in before and after digital photos of patients undergoing topical retinoid monotherapy [37]. To evaluate the effect of topical retinoids on inflammatory lesions, Leyden et al. reviewed high-resolution digital photographs from 577 patients treated with topical retinoids in registration studies [37]. Five blinded investigators rated acne severity before and after 12-15 weeks of monotherapy with topical retinoids (adapalene, tazarotene, or tretinoin). Significant clinical improvement in inflammatory acne was found for all retinoids; in addition, the degree of improvement increased along with worsening baseline acne severity [37]. In a recent systematic review, Jacobs et al. reported that BPO and adapalene both have fast onset of action (defined as time to 25\% reduction in mean inflammatory lesion counts) compared with other retinoids (tretinoin, topical isotretinoin) [41].

\section{Tolerability}

Topical retinoid therapy can be accompanied by cutaneous irritation, including peeling, erythema, irritation, or dryness, which typically 

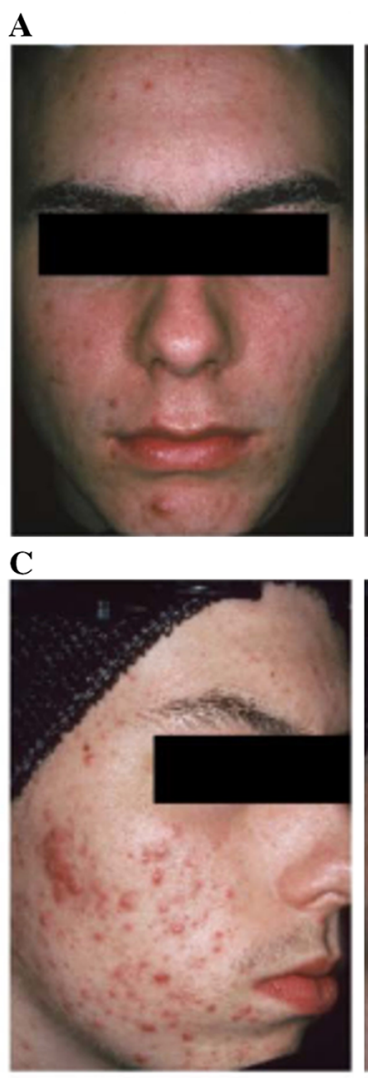
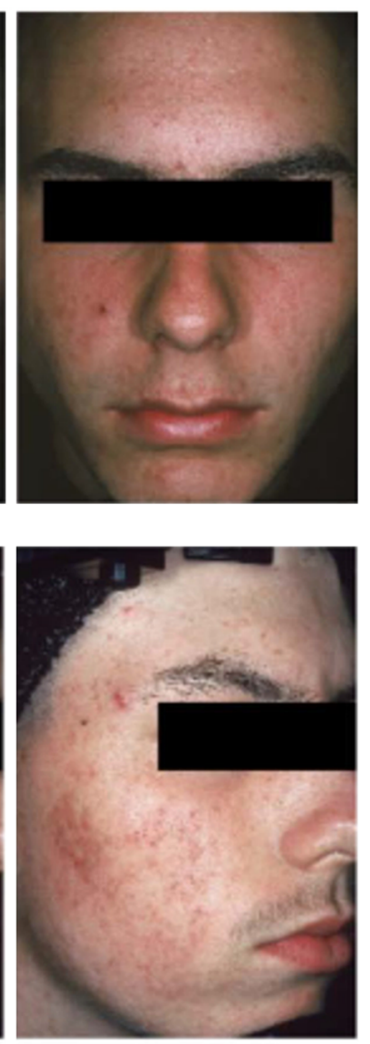

B
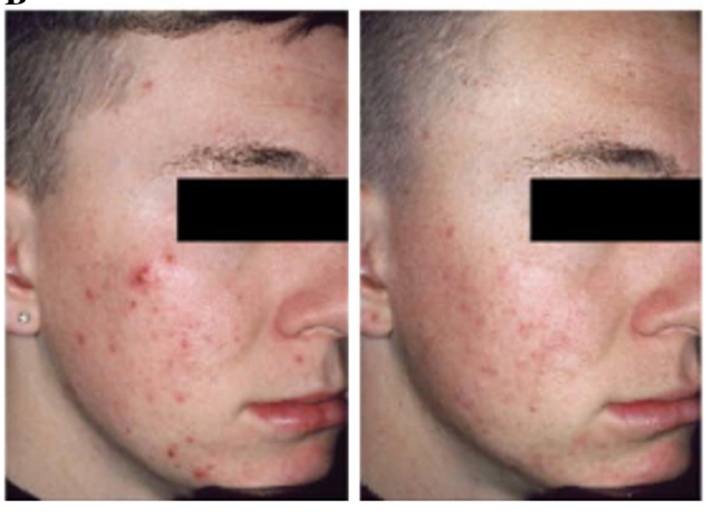

D
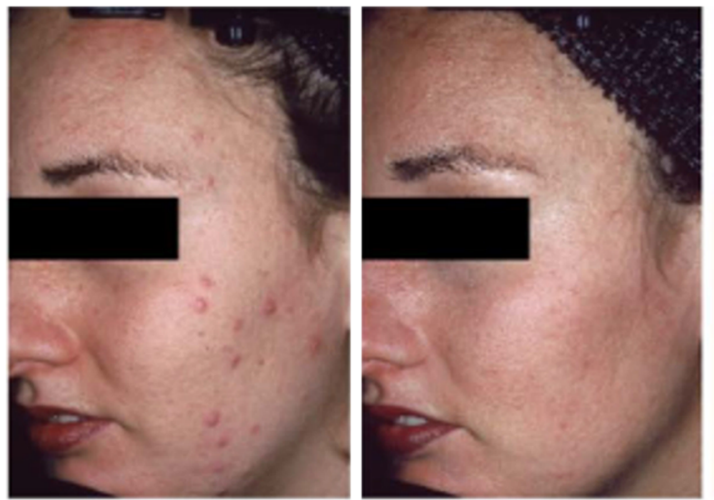

Fig. 3 Clinical efficacy of topical retinoid monotherapy on inflammatory lesions after 12 or 15 weeks therapy. From Leyden et al. [37]

are observed in the first few weeks of treatment and then subside [42]. Clinically, retinoid-induced irritation is superficial, mild to moderate in severity, and limited to the epidermis $[43,44]$. During the process of normalizing desquamation, corneocyte arrangement can be disturbed with loss of cohesion [45-47]. After a few weeks of treatment, the corneocytes are re-arranged, desquamation normalizes, and irritation resolves [45]. In clinical trials of retinoids, the peak of cutaneous irritation typically occurs within the first 1-2 weeks and subsides thereafter [48]. The effect of retinoids on antiinflammatory pathways and on the microcomedo then becomes prominent (Fig. 4) $[13,18,49,50]$.

Retinoids have different receptor binding affinities to their target nuclear hormone receptors (retinoic acid receptors or retinoid $\mathrm{X}$ receptors) and cellular retinoic acid binding protein II (CRABP II) [12], and this variance is believed to account for differences in tolerability [7, 12]. A systematic review of 34 clinical studies (split-face comparisons and parallel designs) showed that the frequency of clinically significant irritation was low with all three available topical retinoids (adapalene, tazarotene, tretinoin) [42]. Among studies with statistically significant results, adapalene gel $0.1 \%$ was the most tolerable retinoid followed by adapalene gel $0.3 \%$. Tazarotene cream $0.1 \%$ and tretinoin $0.025 \%$ had comparable tolerability. Of note, the review authors reported that sensitive skin (history of irritation with facial products) was the most reliable predictor of irritation-superseding the effect of the specific retinoid, concentration, or formulation [42]. Leyden et al. evaluated the facial tolerability of topical retinoids in 253 healthy volunteers in randomized, split-face, investigator-blind studies that took place at one study center with the same investigator [51]. The analysis assessed the 
A

\section{Week 1}
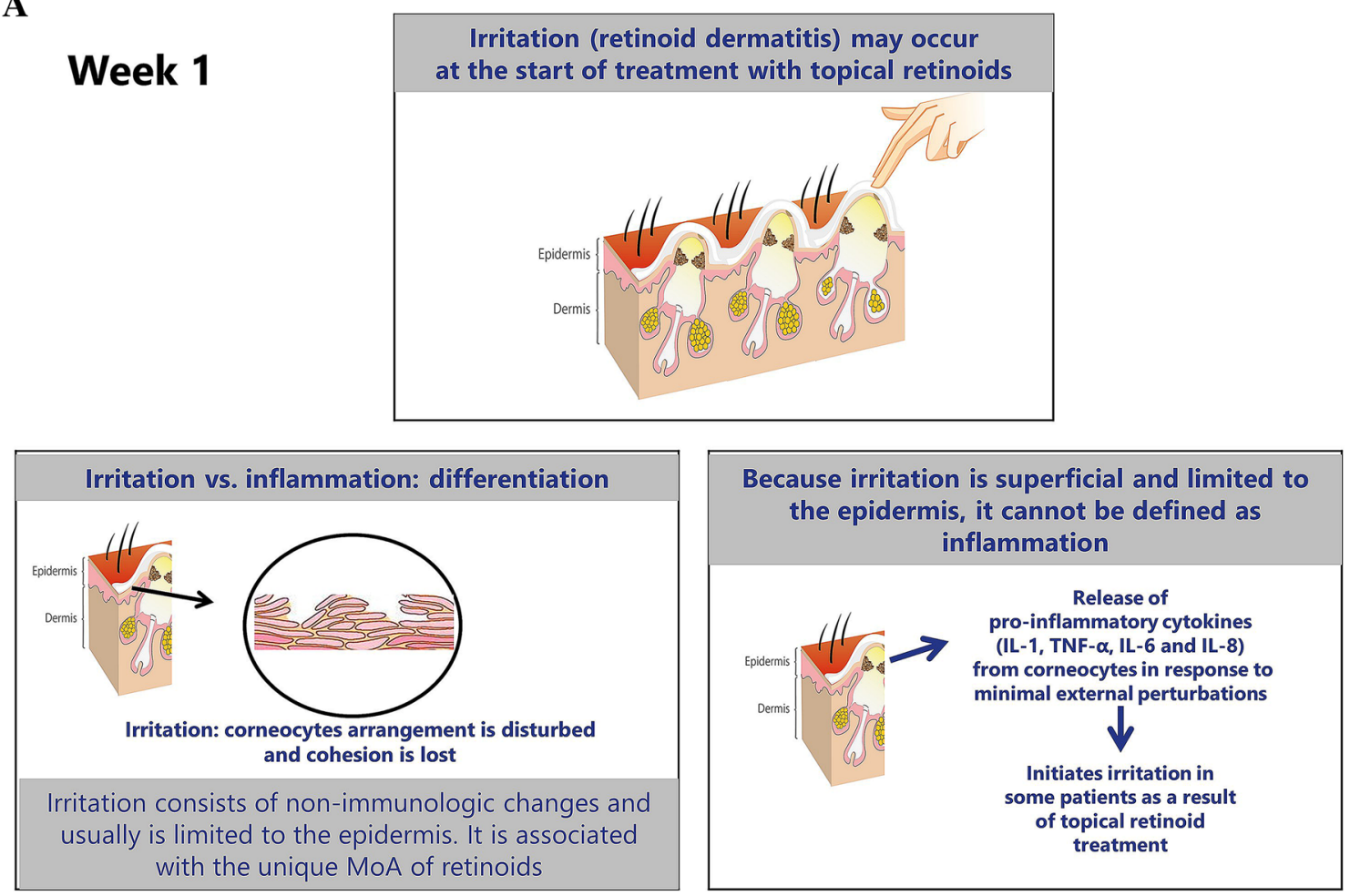

\section{B Weeks 2-4}

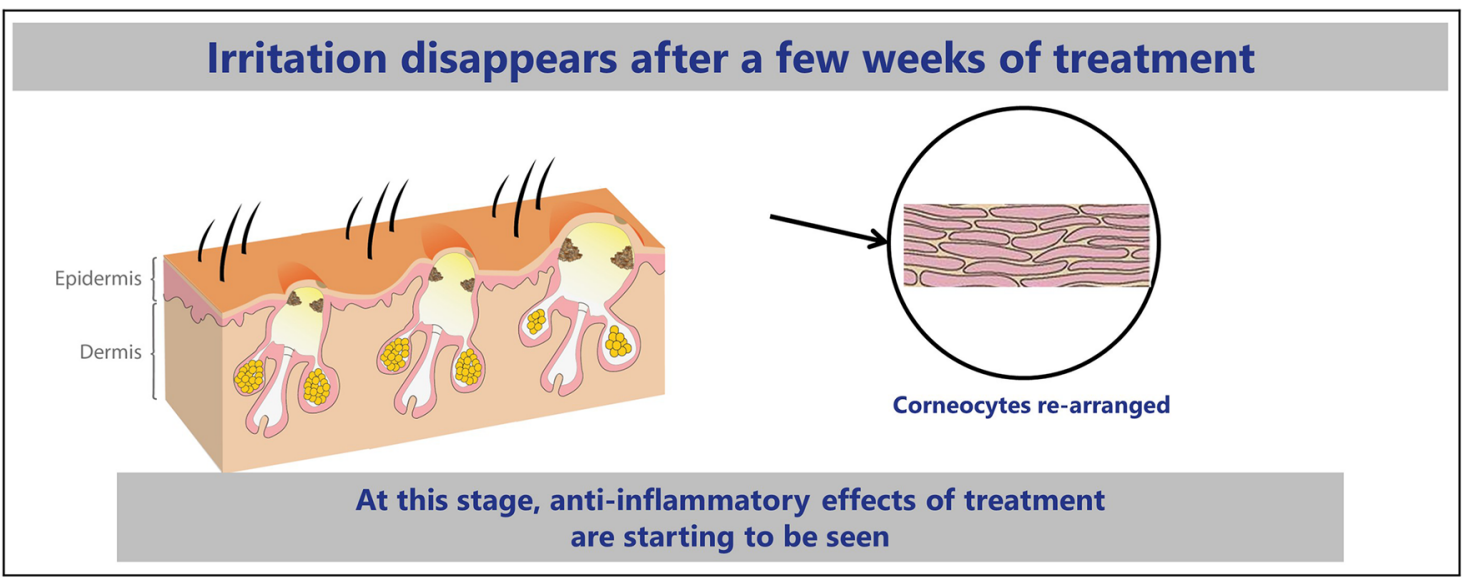

Fig. 4 Changes over time in the skin with retinoid therapy, differentiating transient irritation versus inflammation. Mo $A$ mechanism of action, $I L$ interleukin, $T N F$ tumor necrosis factor

influence of four variables on retinoid tolerability: concentration, vehicle formulation, skin sensitivity, and the specific retinoid. The results indicated that vehicle (gel vs. cream) had an impact on tolerability, but whether gel or cream was best tolerated varied by individual retinoid. Generally, tolerability was better with normal vs. sensitive skin and with lower vs. higher retinoid concentrations. On both normal and sensitive skin, the best tolerated cream was 
tazarotene and the best tolerated gel was adapalene. The results from this study agreed with the systematic review that the sensitivity of the facial skin has at least as much influence on tolerability as the choice of individual retinoid and more than the formulation or concentration [51].

The systematic review also assessed irritation with a fixed-dose combination product versus retinoid monotherapy and concluded that the tolerability of combinations was comparable to monotherapy [42]. Three of the studies included for evaluation allowed the use of moisturizers, and Culp et al. said that moisturizers "may have a larger role in retinoid tolerability than intrinsic factors such as concentration and vehicle" [42]. They emphasize that few patients discontinued clinical trials because of irritation and stress the importance of strategies to minimize irritation [42].

In our clinical experience, there are a number of strategies that can help minimize the potential for irritation and patients with sensitive skin (Table 1) $[52,53]$. Some of these, such as patient education, may require additional staff time but may also reward the practice via improved patient satisfaction with therapeutic outcomes [54].

It is important to encourage patients to optimize their skin care regimens, and patients can benefit from receiving recommendations for appropriate gentle cleansing and moisturizing products $[53,54]$. Good skin care can prepare the stratum corneum for topical therapies in several ways: reducing skin irritation and improving hydration as well as maintaining a correct $\mathrm{pH}$ balance [53]. Generally, antibacterial soaps are not recommended for acne; these agents do not impact $P$. acnes in the follicle and can allow development of gram-negative folliculitis by selective pressure on gram-positive bacteria [53]. Synthetic detergent (syndet) bars and lipid-free cleansers are a better choice, cleansing the skin without a negative impact on epidermal barrier function [53]. Cleansing may be a very important area to address with the patient, since a substantial proportion of people (including medical students) erroneously attribute acne to poor skin hygiene or being dirty $[55,56]$.
Table 1 Strategies to minimize tolerability issues $[7,53,69]$

Take a detailed patient history

Past tolerability problems?

Educate patient

Mild irritation can be part of the treatment process, but usually subsides within 1-2 weeks and can be managed with appropriate steps

How to apply the retinoid in a thin layer (fingertip or pea-sized dose)

Gentle cleansing regimen and avoiding over-cleansing

Select most tolerable retinoid formulation for climate and season

Titrate retinoid dose at initiation

Apply retinoid every other day for first 2-4 weeks (based on clinical trial evidence that this is when irritation is most likely to occur)

Apply a gentle, non-comedogenic moisturizer

Use a short contact method for the first 2-4 weeks (apply retinoid to full face for 30-60 min then wash off)

Predicting which patients will be susceptible to retinoid irritation poses a clinical challenge [57]. A 2014 study designed to evaluate predictors of irritation with tretinoin cream $(n=324)$ reported $61 \%$ of subjects had local adverse effects. Increased risk for side effects was associated with the use of other topical medications (OR 1.88, 95\% CI 1.15-3.08) [57]. Thus, when utilizing topical tretinoin as part of a combination regimen-as is recommended for most patients with acne-it may be prudent to utilize one or more of the strategies listed in Table 1.

\section{Necessity of Treatment Directed Toward P. acnes}

Although $P$. acnes is thought to have a role in acne pathogenesis, that role remains unclear. Acne is not a traditional infectious disease, and approaches targeted solely to killing $P$. acnes do 
not usually eradicate acne [3]. Today, benzoyl peroxide (BPO) is the recommended topical antimicrobial choice because it limits the potential for microbial resistance-a key factor in today's era of antimicrobial stewardship $[58,59]$. Topical BPO and antibiotics act by reducing $P$. acnes concentrations and suppressing inflammation [2]; however, BPO has potent oxidative activity that achieves a $90 \%$ reduction in $P$. acnes in 7 days, and no bacterial resistance against BPO has been shown to date $[2,60,61]$. In addition, BPO has some comedolytic properties, which occur secondary to reduction of free fatty acids [60]. Topical antibiotics are not recommended as monotherapy, but can be used in combination with BPO [7]. Combination therapy with topical retinoids and antimicrobials targets three major areas of acne pathophysiology: abnormal desquamation, $P$. acnes proliferation, and inflammation [2].

\section{Optimizing Acne Therapy}

From both the patient's and the clinician's viewpoint, the two major goals of acne therapy are: (1) to achieve clearance or almost complete clearance of acne lesions and (2) to minimize the potential for long-lasting acne-related sequelae such as scarring, PIH, and erythema [53]. Optimally, clearance should be sustained by a therapy that can prevent the majority of new lesion formation [53]. A US study demonstrated that $43 \%$ of patients with active acne consulting a dermatologist have scars. As might be intuitive to clinicians, the likelihood of scarring increased with acne severity: $51 \%$ of moderate acne patients had scars, and $77 \%$ of severe acne patients had scars at the time of the acne consultation [62]. Acne often follows a chronic relapsing and remitting course, and it is important to have topical medications that decrease the formation of new lesions by targeting the microcomedo, the precursor of acne lesions [54, 63].

There are a variety of topical retinoid concentrations and formulations currently available, allowing clinicians to design individualized treatment regimens based on the patient's presentation, preferences, and ability to tolerate treatment [12]. Retinoids are also available in fixed-combination formulations with BPO [adapalene-BPO $0.1 \% / 2.5 \%$ and $0.3 \% / 2.5 \%$ (Epiduo $^{\circledR}$ and Epiduo Forte ${ }^{\circledR}$, Galderma Laboratories)] and clindamycin [tretinoin 0.025\%/clindamycin phosphate $1.2 \%$ (Veltin, Aqua Pharmaceuticals; Ziana ${ }^{\circledR}$, Valeant Pharmaceuticals)] [7]. The use of retinoids plus BPO targets multiple pathways and can often eliminate the need for antibiotics, reducing the likelihood of antimicrobial resistance $[2,3]$. Dosage may be increased to improve efficacy, since a dose-dependent relationship has been shown for retinoids. Fixed-dose combination formulations can help to streamline therapy, which may be expected to positively impact adherence.

\section{Synergistic and Additive Effects of Single-Agent Treatment}

Synergistic effects have been reported with the fixed combination of $\mathrm{A} / \mathrm{BPO}$, in both modulation of inflammatory markers and clinical efficacy $[64,65]$. Synergy is a term for when the actions of a combination prove to be greater than what might be expected from the sum of the efficacy of the constituents [66]. In a study of normal skin explants and biopsies from acne papules, Zuliani et al. [64] reported A/BPO exerted a cooperative effect on markers of keratinocyte proliferation/differentiation (Ki67, transglutaminase, and $\alpha 2$ and $\alpha 6$ integrins) and aspects of innate immunity including decreasing interleukin 8 (IL-8) and interleukin 10 (IL-10). Finally, A/BPO had a synergistic effect in reducing $B 4$ defensin [64]. Synergy was also shown in the clinic. Tan et al. analyzed results from large-scale clinical trials involving 3855 patients and found the clinical efficacy of $\mathrm{A} / \mathrm{BPO}$ is greater than would be expected with a purely additive effect [65]. The efficacy of the fixed-dose combination product was significantly greater than its constituent molecules and exceeded the sum of the efficacy of adapalene alone plus BPO alone [65]. To our knowledge, no similar analyses have been performed on the other combination products currently available for the treatment of acne.

In addition, Osman-Ponchet et al. recently reported fixed-combination gels of $\mathrm{A} / \mathrm{BPO}$ 
achieve optimal skin absorption that is also markedly increased at the higher A/BPO dose $(0.3 \%)$ compared with the lower $\mathrm{A} / \mathrm{BPO}$ dose (0.1\%) [67]. Skin penetration with $0.3 \%$ A/BPO was greater than seven times higher than that observed with $0.1 \%$ A/BPO [67]. These results support clinical efficacy findings.

\section{CONCLUSIONS}

The scientific rationale for use of topical retinoids in acne is clear [2, 3, 37]. Clinical data from many thousands of patients show these agents are highly efficacious on both noninflammatory and inflammatory acne lesions [3]. Expert groups and evidence-based guidelines agree that topical retinoids should be considered the foundation of acne therapy. It is our hope that educational efforts can be made for all clinicians treating acne so that patients receive optimal therapy according to today's best practices.

\section{ACKNOWLEDGEMENTS}

The study and article processing charges were funded by Galderma International. All authors had full access to all of the data in this study and take complete responsibility for the integrity of the data and accuracy of the data analysis. All named authors meet the International Committee of Medical Journal Editors (ICMJE) criteria for authorship for this manuscript, take responsibility for the integrity of the work as a whole, and have given final approval for the version to be published. The authors wish to thank Valerie Sanders from Sanders Medical Writing for her writing assistance in preparing this manuscript. Funding for medical writing services was provided by Galderma International. Adapalene-benzoyl peroxide 0.1\%/2.5\% and $0.3 \% / 2.5 \%$ (Epiduo ${ }^{\circledR}$ and Epiduo Forte ${ }^{\circledR)}$ ) are manufactured by Galderma Laboratories, L.P.

Disclosures. Dr. Leyden has served as consultant or advisory board member for Galderma,
Foamix, Novan, Botanix, PhotSonix, Siena, and Allergan. Dr. Stein-Gold has served as investigator, advisor, and speaker for Galderma, Allergan, and Valeant. Dr. Weiss has received grants for research from Galderma, Foamix, Allergan, Valeant, Perrigo, and Promius and honoraria for consulting/advisory boards from Galderma, Foamix, Valeant, Promius, and Novan.

Compliance with Ethics Guidelines. This article is based on previously conducted studies and does not involve any new studies of human or animal subjects performed by any of the authors.

Data Availability. Data sharing is not applicable to this article as no data sets were generated or analyzed during the current study/ review.

Open Access. This article is distributed under the terms of the Creative Commons Attribution-NonCommercial 4.0 International License (http://creativecommons.org/licenses/ by-nc/4.0/), which permits any noncommercial use, distribution, and reproduction in any medium, provided you give appropriate credit to the original author(s) and the source, provide a link to the Creative Commons license, and indicate if changes were made.

\section{REFERENCES}

1. Pena S, Hill D, Feldman SR. Use of topical retinoids by dermatologists and non-dermatologists in the management of acne vulgaris. J Am Acad Dermatol. 2016;74:1252-4.

2. Gollnick H, Cunliffe W, Berson D, Dreno B, Finlay A, Leyden JJ, et al. Management of acne: a report from a Global Alliance to Improve Outcomes in Acne. J Am Acad Dermatol. 2003;49:S1-37.

3. Thiboutot D, Gollnick H, Bettoli V, Dreno B, Kang $\mathrm{S}$, Leyden JJ, et al. New insights into the management of acne: an update from the Global Alliance to Improve Outcomes in Acne group. J Am Acad Dermatol. 2009;60:S1-50.

4. Eichenfield LF, Krakowski AC, Piggott C, Del Rosso J, Baldwin H, Friedlander SF, et al. Evidence-based recommendations for the diagnosis and treatment 
of pediatric acne. Pediatrics. 2013;131(Suppl 3):S163-86.

5. Nast A, Dreno B, Bettoli V, Degitz K, Erdmann R, Finlay AY, et al. European evidence-based (S3) guidelines for the treatment of acne. J Eur Acad Dermatol Venereol. 2012;26(Suppl 1):1-29.

6. Strauss JS, Krowchuk DP, Leyden JJ, Lucky AW, Shalita AR, Siegfried EC, et al. Guidelines of care for acne vulgaris management. J Am Acad Dermatol. 2007;56:651-63.

7. Zaenglein AL, Pathy AL, Schlosser BJ, Alikhan A, Baldwin HE, Berson DS, et al. Guidelines of care for the management of acne vulgaris. J Am Acad Dermatol. 2016;74(945-73):e33.

8. Balkrishnan R, Fleischer AB Jr, Paruthi S, Feldman SR. Physicians underutilize topical retinoids in the management of acne vulgaris: analysis of US National Practice Data. J Dermatolog Treat. 2003;14:172-6.

9. Balkrishnan R, Bhosle MJ, Camacho F, Fleischer AB, Feldman SR. Prescribing patterns for topical retinoids: analyses of 15 years of data from the national ambulatory medical care survey. J Dermatolog Treat. 2010;21:193-200.

10. Gollnick HP, Bettoli V, Lambert J, Araviiskaia E, Binic I, Dessinioti C, et al. A consensus-based practical and daily guide for the treatment of acne patients. J Eur Acad Dermatol Venereol. 2016;30:1480-90.

11. Plewig GK. A. Acne and Rosacea. New York: Springer; 2000.

12. Thielitz A, Abdel-Naser MB, Fluhr JW, Zouboulis CC, Gollnick H. Topical retinoids in acne-an evidence-based overview. J Dtsch Dermatol Ges. 2008;6:1023-31.

13. Dreno B, Gollnick HP, Kang S, Thiboutot D, Bettoli $\mathrm{V}$, Torres $\mathrm{V}$, et al. Understanding innate immunity and inflammation in acne: implications for management. J Eur Acad Dermatol Venereol. 2015;29(Suppl 4):3-11.

14. Jeremy AH, Holland DB, Roberts SG, Thomson KF, Cunliffe WJ. Inflammatory events are involved in acne lesion initiation. J Invest Dermatol. 2003;121:20-7.

15. Do TT, Zarkhin S, Orringer JS, Nemeth S, Hamilton $\mathrm{T}$, Sachs D, et al. Computer-assisted alignment and tracking of acne lesions indicate that most inflammatory lesions arise from comedones and de novo. J Am Acad Dermatol. 2008;58:603-8.

16. Lee WJ, Jung HJ, Lim HJ, Jang YH, Lee SJ, Kim DW. Serial sections of atrophic acne scars help in the interpretation of microscopic findings and the selection of good therapeutic modalities. J Eur Acad Dermatol Venereol. 2013;27:643-6.

17. Vowels BR, Yang S, Leyden JJ. Induction of proinflammatory cytokines by a soluble factor of Propionibacterium acnes: implications for chronic inflammatory acne. Infect Immun. $1995 ; 63: 3158-65$.

18. Thielitz A, Helmdach M, Ropke EM, Gollnick H. Lipid analysis of follicular casts from cyanoacrylate strips as a new method for studying therapeutic effects of antiacne agents. $\mathrm{Br} \mathrm{J}$ Dermatol. 2001;145:19-27.

19. Czernielewski J, Michel S, Bouclier M, Baker M, Hensby JC. Adapalene biochemistry and the evolution of a new topical retinoid for treatment of acne. J Eur Acad Dermatol Venereol. 2001;15(Suppl 3):5-12.

20. Michel S, Jomard A, Demarchez M. Pharmacology of adapalene. Br J Dermatol. 1998;139(Suppl 52):3-7.

21. Tenaud I, Khammari A, Dreno B. In vitro modulation of TLR-2, CD1d and IL-10 by adapalene on normal human skin and acne inflammatory lesions. Exp Dermatol. 2007;16:500-6.

22. Thielitz A, Gollnick H. Topical retinoids in acne vulgaris: update on efficacy and safety. Am J Clin Dermatol. 2008;9:369-81.

23. Yeh L, Bonati LM, Silverberg NB. Topical retinoids for acne. Semin Cutan Med Surg. 2016;35:50-6.

24. Griffiths CE, Finkel LJ, Tranfaglia MG, Hamilton TA, Voorhees JJ. An in vivo experimental model for effects of topical retinoic acid in human skin. Br J Dermatol. 1993;129:389-94.

25. Lavker RM, Leyden JJ, Thorne EG. An ultrastructural study of the effects of topical tretinoin on microcomedones. Clin Ther. 1992;14:773-80.

26. Thiboutot D, Pariser DM, Egan N, Flores J, Herndon $\mathrm{JH} \mathrm{Jr}, \mathrm{Kanof} \mathrm{NB}$, et al. Adapalene gel $0.3 \%$ for the treatment of acne vulgaris: a multicenter, randomized, double-blind, controlled, phase III trial. J Am Acad Dermatol. 2006;54:242-50.

27. Pariser DM, Thiboutot DM, Clark SD, Jones TM, Liu Y, Graeber M, et al. The efficacy and safety of adapalene gel $0.3 \%$ in the treatment of acne vulgaris: a randomized, multicenter, investigator-blinded, controlled comparison study versus adapalene gel $0.1 \%$ and vehicle. Cutis. 2005;76:145-51.

28. Stein Gold L, Weiss J, Rueda MJ, Liu H, Tanghetti E. Moderate and severe inflammatory acne vulgaris effectively treated with single-agent therapy by a 
new fixed-dose combination adapalene 0.3\%/benzoyl peroxide $2.5 \%$ gel: a randomized, double-blind, parallel-group, controlled study. Am J Clin Dermatol. 2016;17:293-303.

29. Fabbrocini G, Annunziata MC, D'Arco V, De Vita V, Lodi G, Mauriello MC, et al. Acne scars: pathogenesis, classification and treatment. Dermatol Res Pract. 2010;2010:893080.

30. Patel M, Leung S, Chien AL, Xu H, Audibert F, Kerrouche N, Rueda MJ, Kang S. Improvement in atrophic acne scars by topical adapalene $0.3 \%$ gel is associated with induction of procollagen I and III. Society of Investigative Dermatology. Albuquerque, NM2014.

31. Pandya AG, Guevara IL. Disorders of hyperpigmentation. Dermatol Clin. 2000;18:91-8 (ix).

32. Grimes $\mathrm{P}$, Callender V. Tazarotene cream for postinflammatory hyperpigmentation and acne vulgaris in darker skin: a double-blind, randomized, vehicle-controlled study. Cutis. 2006;77:45-50.

33. Tanghetti E, Dhawan S, Green L, Del Rosso J, Draelos Z, Leyden J, et al. Randomized comparison of the safety and efficacy of tazarotene $0.1 \%$ cream and adapalene $0.3 \%$ gel in the treatment of patients with at least moderate facial acne vulgaris. J Drugs Dermatol. 2010;9:549-58.

34. Griffiths CE, Finkel LJ, Ditre CM, Hamilton TA, Ellis $\mathrm{CN}$, Voorhees JJ. Topical tretinoin (retinoic acid) improves melasma. A vehicle-controlled, clinical trial. Br J Dermatol. 1993;129:415-21.

35. Jacyk WK, Mpofu P. Adapalene gel 0.1\% for topical treatment of acne vulgaris in African patients. Cutis. 2001;68:48-54.

36. Bulengo-Ransby SM, Griffiths CE, Kimbrough-Green CK, Finkel LJ, Hamilton TA, Ellis CN, et al. Topical tretinoin (retinoic acid) therapy for hyperpigmented lesions caused by inflammation of the skin in black patients. $\mathrm{N}$ Engl $\mathrm{J}$ Med. 1993;328:1438-43.

37. Leyden JJ, Shalita A, Thiboutot D, Washenik K, Webster G. Topical retinoids in inflammatory acne: a retrospective, investigator-blinded, vehicle-controlled, photographic assessment. Clin Ther. 2005;27:216-24.

38. Shalita A, Weiss JS, Chalker DK, Ellis CN, Greenspan A, Katz HI, et al. A comparison of the efficacy and safety of adapalene gel $0.1 \%$ and tretinoin gel $0.025 \%$ in the treatment of acne vulgaris: a multicenter trial. J Am Acad Dermatol. 1996;34:482-5.

39. Webster GF, Berson D, Stein LF, Fivenson DP, Tanghetti EA, Ling M. Efficacy and tolerability of once-daily tazarotene $0.1 \%$ gel versus once-daily tretinoin $0.025 \%$ gel in the treatment of facial acne vulgaris: a randomized trial. Cutis. 2001;67:4-9.

40. Webster GF, Guenther L, Poulin YP, Solomon BA, Loven K, Lee J. A multicenter, double-blind, randomized comparison study of the efficacy and tolerability of once-daily tazarotene $0.1 \%$ gel and adapalene $0.1 \%$ gel for the treatment of facial acne vulgaris. Cutis. 2002;69:4-11.

41. Jacobs A, Starke G, Rosumeck S, Nast A. Systematic review on the rapidity of the onset of action of topical treatments in the therapy of mild-to-moderate acne vulgaris. $\mathrm{Br} \mathrm{J}$ Dermatol. 2014;170:557-64.

42. Culp L, Moradi Tuchayi S, Alinia H, Feldman SR. Tolerability of topical retinoids: are there clinically meaningful differences among topical retinoids? J Cutan Med Surg. 2015;19:530-8.

43. Mukherjee S, Date A, Patravale V, Korting HC, Roeder A, Weindl G. Retinoids in the treatment of skin aging: an overview of clinical efficacy and safety. Clin Interv Aging. 2006;1:327-48.

44. Kim BH, Lee YS, Kang KS. The mechanism of retinol-induced irritation and its application to anti-irritant development. Toxicol Lett. 2003;146:65-73.

45. Fore-Pfliger J. The epidermal skin barrier: implications for the wound care practitioner, part I. Adv Skin Wound Care. 2004;17:417-25.

46. Dunlap FE, Baker MD, Plott RT, Verschoore M. Adapalene $0.1 \%$ gel has low skin irritation potential even when applied immediately after washing. Br J Dermatol. 1998;139(Suppl 52):23-5.

47. Haidl G, Plewig G. Exfoliative cytology of stratum corneum and the effects of topical retinoids on the physical properties of corneocytes. J Soc Cosmet Chem. 1988;39:53-67.

48. Callender VD, Preston N, Osborn C, Johnson L, Gottschalk RW. A Meta-analysis to investigate the relation between Fitzpatrick skin types and tolerability of adapalene-benzoyl peroxide topical gel in subjects with mild or moderate acne. J Clin Aesthet Dermatol. 2010;3:15-9.

49. Becherel PA, Mossalayi MD, LeGoff L, Frances C, Chosidow O, Debre P, et al. Mechanism of anti-inflammatory action of retinoids on keratinocytes. Lancet. 1994;344:1570-1.

50. Thielitz A, Krautheim A, Gollnick H. Update in retinoid therapy of acne. Dermatol Ther. 2006;19:272-9. 
51. Leyden J, Grove G, Zerweck C. Facial tolerability of topical retinoid therapy. J Drugs Dermatol. 2004;3:641-51.

52. Bershad S, Kranjac Singer G, Parente JE, Tan MH, Sherer DW, Persaud AN, et al. Successful treatment of acne vulgaris using a new method: results of a randomized vehicle-controlled trial of short-contact therapy with $0.1 \%$ tazarotene gel. Arch Dermatol. 2002;138:481-9.

53. Levin J. The relationship of proper skin cleansing to pathophysiology, clinical benefits, and the concomitant use of prescription topical therapies in patients with acne vulgaris. Dermatol Clin. 2016;34:133-45.

54. Thiboutot D, Dreno B, Layton A. Acne counseling to improve adherence. Cutis. 2008;81:81-6.

55. Tan JK, Vasey K, Fung KY. Beliefs and perceptions of patients with acne. J Am Acad Dermatol. 2001;44:439-45.

56. Green J, Sinclair RD. Perceptions of acne vulgaris in final year medical student written examination answers. Australas J Dermatol. 2001;42:98-101.

57. Pomerantz $H$, Weinstock MA. Veterans affairs topical tretinoin chemoprevention G. Predictors of local adverse effects caused by topical tretinoin cream $0.1 \%$ in the veterans affairs topical tretinoin chemoprevention trial. $\mathrm{Br} \mathrm{J}$ Dermatol. 2014;171:642-5.

58. Thiboutot D, Dreno B, Gollnick H, Bettoli V, Kang $\mathrm{S}$, Leyden JJ, et al. A call to limit antibiotic use in acne. J Drugs Dermatol. 2013;12:1331-2.

59. Dreno B, Thiboutot D, Gollnick H, Bettoli V, Kang $\mathrm{S}$, Leyden JJ, et al. Antibiotic stewardship in dermatology: limiting antibiotic use in acne. Eur J Dermatol. 2014;24:330-4.

60. Hegemann L, Toso SM, Kitay K, Webster GF. Anti-inflammatory actions of benzoyl peroxide: effects on the generation of reactive oxygen species by leucocytes and the activity of protein kinase $\mathrm{C}$ and calmodulin. Br J Dermatol. 1994;130:569-75.
61. Bojar RA, Cunliffe WJ, Holland KT. The short-term treatment of acne vulgaris with benzoyl peroxide: effects on the surface and follicular cutaneous microflora. Br J Dermatol. 1995;132:204-8.

62. Tan J, Kang S, Leyden J. Prevalence and risk factors of acne scarring among patients consulting dermatologists in the Unites States. J Drugs Dermatol. 2017;16:97-102.

63. Gollnick HP, Finlay AY, Shear N. Global alliance to improve outcomes in A. Can we define acne as a chronic disease? If so, how and when? Am J Clin Dermatol. 2008;9:279-84.

64. Zuliani T, Khammari A, Chaussy H, Knol AC, Dreno B. Ex vivo demonstration of a synergistic effect of Adapalene and benzoyl peroxide on inflammatory acne lesions. Exp Dermatol. 2011;20:850-3.

65. Tan J, Gollnick HP, Loesche C, Ma YM, Gold LS. Synergistic efficacy of adapalene $0.1 \%$-benzoyl peroxide $2.5 \%$ in the treatment of 3855 acne vulgaris patients. J Dermatolog Treat. 2011;22:197-205.

66. Kircik LH. Synergy and its clinical reievance in topical acne therapy. J Clin Aesthet Dermatol. 2011;4:30-3.

67. Osman-Ponchet H, Sevin K, Gaborit A, Wagner N, Poncet M. Fixed-combination gels of adapalene and benzoyl peroxide provide optimal percutaneous absorption compared to monad formulations of these compounds: results from two in vitro studies. Dermatol Ther (Heidelb). 2016;7:123-31.

68. Weiss J, Stein Gold L, Leoni M, Rueda MJ, Liu H, Tanghetti E. Customized single-agent therapy management of severe inflammatory acne: a randomized, double-blind, parallel-group, controlled study of a new treatment-adapalene 0.3\%-benzoyl Peroxide 2.5\% Gel. J Drugs Dermatol. 2015;14:1427-35.

69. Ikoma ATJ, Bissonnette R, Gratton D, Kerrouche N. Enhancing tolerability to adapalene $0.1 \%$ /benzoyl peroxide $2.5 \%$ gel in acne patients: a randomized controlled trial of 4 different application regimens. Presented at 4th Eastern Asia Conference, Nov 16-18, 2016 Tokyo, Japan. 2016. 